\title{
关于初中英语教学方法创新思路的探讨
}

\author{
张相荣 \\ 山东省单县实验中学 \\ DOI:10.32629/er.v2i1.1622
}

[摘 要] 随着我国新课程改革进程的不断推动, 我国初中英语教学成为了课程改革中的重点内容, 针对当前的情形, 相关初中 英语教师应认真分析当前的英语教学办法, 不断进行改革与创新。因此, 本文就将重点围绕我国当前初中英语教学环境的现状, 进行分析与总结,并进一步阐述应对初中英语教学改革的创新举措,提供一些借鉴意义。

[关键词] 初中英语; 教学方法; 创新思路

如今, 随着新课程改革的逐年推进, 初中英语的教学开 始步入一个全面的新阶段, 英语教学开始逐渐渗入到我们的 日常生活中来。我们知道, 初中是学习英语基础知识的阶段, 但是现阶段我国很多初中英语教学模式尚存在诸多问题亟 待解决, 诸如在教学方式上缺乏创新思路、缺乏新的教学模 式等现象, 那么接下来, 本文就将主要分析我国当前初中英 语教学环境的现状, 进而提出相关行之有效的初中英语教学 改革举措。

\section{1 当前初中英语教学环境的现状}

我国当前初中英语教学环境中尚存在非常多的问题, 首 先, 在初中阶段, 由于英语是第二语言, 因此很多学生在学习 的进程中觉得难学, 特别是一些男同学, 一般会在初中阶段 缺少甚至失去对英语学习的兴致和热情。其次, 相关初中英 语教师在讲课过程中仅仅是一味的单方面授课, 缺乏相应有 效的讲课手段和方法, 不能使学生有效地融入至初中英语课 堂的学习氛围中, 从而减少了初中生的学习兴趣和激情, 久 而久之, 部分初中生可能会放弃英语的学习。由此可见, 对初 中英语教学办法进行探讨和创新是必不可少的。

\section{2 如何对初中英语教学进行创新改革}

(1) 加强对英语音标的学习

初中英语教学创新改革的首要举措便是要加强对英语 音标的学习, 初中英语教学中最为主要和基础的就是学生对 英语音标的学习, 音标的学习关系着学生记忆单词的效率和 拼读单词的准确性。诸如, 初中英语教材中 environment (环 境) 这个单词, 单词的长度较长, 但是其发音时间却较短, 尤 其是 en 发 $[I n]$ 的音, v iron 发 [' varnish] 的音, 而 ment 则 是一个固定发音 [mnt], 这三个音阶连接在一起就是这个单 词的全部发音了, 且重音是区分单词的关键项, 是否有重音 对单词的拼读有着巨大的影响, 相关初中英语教师应当重视 音标的教学工作, 提升初中生的单词拼读能力。

(2) 研究更为简单的单词记忆方法

初中英语教学创新改革的第二个重要举措便是要研究 更为简单的单词记忆法, 帮助学生更快捷的记忆单词, 促进 其拼写单词的效率。诸如, 初中英语教材中 marathon [' $\mathrm{mr} \theta$ $\mathrm{n}]$ (马拉松) 这个单词, 在英语发音中与中文发音较为接近,
是由英文翻译演变而来, 帮助学生科学的梳理这类单词, 快 速进行单词的记忆。除此以外, family (家庭) 这个单词可以 理解成 Father and mother i love you 这句话每个单词首 字母的缩写, 以此类方式提升初中生在英语学习中的关联性 思维。

(3) 对英语课堂教学进行改革

初中英语教学创新改革的第三个重要举措便是要对英 语课堂教学适时进行改革, 增加一些趣味性的英语学习环节, 现阶段很多初中英语教学模式都是以教师讲课为主, 形式单 一且枯燥, 需要相关英语教师适时进行变革, 借鉴优秀英语 课堂, 使初中英语的学习变成学生的兴趣学科。英语教师可 以定期将一些英语游戏融入进传统的课堂中, 达到快乐学习 英语的目的, 诸如, 运用常见的击鼓传花游戏, 进行单词调动 和积累的教学目的, 选取物品进行前后传递, 停止敲击的时 候, 率先请 $\mathrm{A}$ 同学随意说一个课本英文单词, 当再次传到下 一个人时, 就经由 $\mathrm{B}$ 同学说出 $\mathrm{A}$ 同学单词中, 以最后一个字母 为开头的英文单词, 并进行相应的拼写, 以此类推。此举不仅 能够提升学生的记单词能力, 也能增强其对英语学习的激情 和兴致。

(4) 充分发挥学生的主体性特征

初中英语教学创新改革的第四个重要举措便是要充分 发挥学生的主体性特征, 首先, 要改变传统教师教和学生学 的英语教学模式, 这类英语教学模式不仅缺乏正常师生间的 良好互动, 而且长期运用这类教学模式, 会致使学生形成一 种潜在的情性, 从而影响学生学习英语的积极性和自主性。 因此, 对现阶段初中英语教学进行适时变更是势在必行的。 诸如, 初中英语教师在备课时, 可以把全班同学分为几个小 组, 并在分配的时候合理把控组员间的英语水平, 要有差异 性。小组内的成员要依据学习成绩能力进行有高有低的互补, 同时依据实际课堂情况科学的重新分配英语课堂座位, 使得 各英语小组聚在一起上课, 英语教师在课堂讲授过程中, 只 是起到简单的引导工作, 具体的教学目标和教学内容由学生 在小组中讨论完成, 英语教师在每组进行成果展示后, 最终 进行一个总体的梳理、总结以及补充概括的工作, 与此同时, 在具体的英语课堂讲解试题时, 英语教师就可以给每个组都 
分配一些题目, 并经由组内举荐的学生来进行轮换讲解, 特 别是针对 that、which、where 等定语从句的题型和 v-ed、 $v^{-}$ing、 $v^{-}$s/es 等区分句子语态时态的题型, 一旦发觉学生 在讲解时出先常态错误, 就要引起高度的重视, 及时进行全 班范围内的讲解和修正。通过此类教学手段, 不仅能够提升 学生的英语学习自主性, 而且能够使得同班同学形成良好互 助的班风。

(5)看重语法的教学活动

初中英语教学创新改革的第五个重要举措便是要看重 语法的教学活动, 需要相关英语教师在语法教学中加强对英 语语法的训练和锻炼, 诸如主语从句、定语从句以及虚拟语 气等内容, 相关初中英语教师务必要求学生掌握几类语法学 习的能力, 同时在日常训练中增加相应语法的内容锻炼, 通 过量的累积, 促使学生对基本的常用语法有基本的了解和使 用能力。

(6) 有效运用多媒体技术辅助英语教学

初中英语教学创新改革的第六个重要举措便是要有效 运用多媒体技术辅助英语的教学活动, 初中英语的授课群体 多在 12-15 岁这个阶段, 这些学生对于新鲜事物具有强烈的 感知力和好奇心, 喜爱多媒体、计算机以及网络等高科技技 术。相关初中英语教师应当依据这些实际情形, 科学有效的 将教学手段与多媒体进行结合, 促使初中英语教学水平不断 提升。总体而言, 应充分运用多媒体媒介的教学手段, 不断丰 富英语教学的形式和内容, 从而激发出学生的初中英语学习 兴致, 而现阶段的多媒体技术, 包含计算机技术、现代电子技 术以及网络技术等综合性教学的手段与媒介, 合理的运用英 语多媒体课件, 不仅能够展现新型的教学思路, 而且能够对 初中英语教学提供指导意义和应用价值。我们知道, 通过多 媒体课件来辅助英语教学, 是初中英语教育的必要手段, 也 是广大初中生的基础诉求。诸如, 英语教师在日常授课时,
要依照课文内容与教材目标, 适当选取合理的内容将其制作 成 PPT 课件, 利用课件中愉悦的音乐、优美的画质、绚烂的 文章以及动感的视频等元素, 进行综合考量和统一的装帧、 设计与制作, 在讲授时将课件放映出来。这样既方便了英语 教师的点拨、解析和讲授, 也能够有效引领学生的注意力, 激发他们的兴趣, 使其感受到英语学习的无限鬼力。除此以 外, 相关初中英语教师应多多利用多媒体技术的其他手段, 在初中英语教学中树立独具一格的讲课风格, 形成自己的新 型授课模式和完整健全的英语思维链条, 帮助学生全神贯注 的投入进英语课堂学习中, 也能够引发自身对英语教学的探 究和思考, 由此可见, 这项应用是具有明确指导价值和重大 现实意义的, 值得去进行完善和推广。

\section{3 结束语}

根据上述分析可以看出, 我国初中英语教学成为了课程 改革中的重点内容, 针对当前的情形, 需要相关初中英语教 师认真分析当前的英语教学办法, 不断进行改革与创新。具 体可以通过加强对英语音标的学习、研究更为简单的单词记 忆方法、充分发挥学生的主体性特征、注重语法的教学活动 以及运用多媒体技术辅助英语教学等手段来进行完善, 只要 相关英语教师认真钻研, 就一定会促进初中英语教学方法的 改革与创新。

\section{[参考文献]}

[1]刘否, 刘文铎. 《英语教学办法》, 清华出版 社,2016:12-13.

[2]王丽娜。《对学生进行教学改革前后对比》,人民教育 出版社,2016:13.

[3]于春华.初中英语教学方法的创新运用 [J]. 青海教 育,2017(Z1):62.

[4]李维娜.初中英语教学方法创新途径分析[J].校园英 语,2016(06):103. 